\title{
An appraisal of plain language in the South African banking sector
}

\author{
Eleanor Cornelius \\ Department of Linguistics, University of Johannesburg, South Africa \\ E-mail: eleanorc@uj.ac.za
}

\begin{abstract}
The Consumer Protection Act 68 of 2008 (CPA) came into full force in April 2011. An important corollary of this Act, and the National Credit Act 34 of 2005, is the obligation that consumer documents must be in plain language. It has long been debated whether it is possible to make legal documents available in plain language for lay consumption. The aim of this study is to investigate the successes and failures of the plain language project five years after the CPA became operational. This study relies on data collected through focus group interviews with bank employees in both language units and legal divisions.
\end{abstract}

Findings indicate that, in general, both legal and language practitioners concur that legal documents can be simplified under certain conditions, although consensus has not been reached about the degree of simplification and the types of legal documents that can be simplified. Interviewees experience difficulty with the vagueness of the plain language obligation. Findings also show that legal practitioners are concerned about prejudicing the legal status of documents and are reluctant to deviate from traditional styles of drafting. According to the language practitioners interviewed, legal practitioners use this as an excuse to avoid plain language, and lack of clear enforcement measures for non-compliance results in windowdressing and paying lip service to the intent of the plain language obligation. Findings also reveal that the location of the language services unit in the institution has a marked effect on the successful implementation of plain language in the banking sector. Banks prefer a combination of approaches to plain language, but no testing is done on real consumers. Among others, poor coordination, outsourcing, lack of (ongoing) training, limited use of indigenous languages and the absence of dedicated plain language style guides impact success.

Based on the findings of this study, a model for plain language in the financial services and other industries is proposed.

Keywords: banking sector, compliance, language services, legal practitioner, language practitioner, model for plain language 


\subsection{Introduction}

A new era for language practice has been introduced in present-day South Africa with the promulgation of the National Credit Act 34 of 2005 (NCA) and the Consumer Protection Act 68 of 2008 (CPA). In the spirit of democracy and in keeping with the Constitution, these pieces of legislation afford consumers wide protection, and promote the use of understandable language in consumer documents. The right to information in plain and understandable language is now a basic right of consumers. The objective is, among others, to prevent practices where vulnerable consumers enter into agreements of which they do not fully understand its content and consequences. Traditional styles of legal drafting result in texts that often exceed the processing capacity of lay readers, rendering such readers vulnerable. This creates a language-based problem "with a clear language component" (Webb and Kembo-Sure 2004: 3). The field of applied linguistics is where solutions to such real-world language problems are pursued. Gibbons (2004: 285) suggests three phases to approach real-world language problems: (i) the reflection stage during which a language problem is revealed and analysed; (ii) an action stage during which treatment or intervention is developed; and (iii) an evaluation stage to determine the success of the treatment or intervention. This study represents an effort to evaluate the success and failures of the plain language project in the banking sector in contemporary South Africa.

The recent plain language enterprise in South Africa affects not only the consumer industry, but also the language profession. According to Cornelius (2012: 8-9) the plain language provisions in the NCA and CPA create a practical dilemma of who might be best qualified to apply plain language: Those who are legally trained, or those with training in languages and/or linguistics? Two resulting questions arise:

- Do language practitioners have the required knowledge, skills and expertise to accurately convey complex legal concepts and ideas in plain and understandable language without risk to legal status and legal consequence?

- Conversely, do legal practitioners have the required (text)linguistic and other related knowledge and skills to enhance consumers' understanding of the content and significance of a complex legal text such as a credit agreement?

It seems the solution may be multidisciplinary collaboration between language practitioners, employed in the language offices of financial services providers, such as banks, and legal practitioners employed by the same institution. The rare mix of legal knowledge, knowledge of language and knowledge of text linguistics can hardly ever be found in one single person. If the language units and legal divisions do not collaborate, and if they do not depart from a common understanding of what plain language is (including its potential and limitations) and their respective roles in and contributions to the plain language project, the project is doomed to fail. The result may be the exact opposite of what both the CPA and NCA envisage, and the providers of services and goods may end up paying lip service to the plain language provisions by effecting only superficial modifications in their documents in order to comply (Cornelius 2012: 8-9).

It has long been debated whether it is possible to make complex legal documents available in plain language for lay consumption. The aim of this paper is to investigate the successes and failures of the plain language project in the banking sector in South Africa, five years after the 
implementation of the CPA in April 2011. Reflecting on the practices followed in the banking sector since the inception of the NCA and the CPA, this study is guided by the following research question: Is it possible to make available complex, legally binding documents in plain language and if so, how can this be achieved?

These questions were answered by conducting focus group interviews with employees of both language offices and legal divisions in three major banks. Debates about the possibilities and limitations of plain language are briefly discussed below; followed by a discussion of the "plain language' definition in relation to other definitions of plain language, before the findings of the study are presented and discussed. Finally, a model for plain language in the banking sector is presented.

\section{Debates about plain language}

Ever since the development of the plain language movement during the $1960 \mathrm{~s}$ and $1970 \mathrm{~s}$ elsewhere in the world, it has been debated, in both legal and linguistic circles, whether it is indeed possible to make complex (legal) documents, containing complex (legal) concepts and ideas, available in plain language for lay audiences (Kimble 1998-2000; 1994-1995). There are those who are highly sceptical of plain language. Kimble (1994-1995) summarises the debates at the time and refers to the old and the new criticism. The old criticism comes principally from within the legal fraternity. According to Kimble (1994-1995), supporters of this type of criticism claim that it is not possible to convey complex legal ideas in anything other than legalese. The new criticism comes mainly from outside the legal profession. These critics hold, among others, that there is no concrete proof that the use of plain language enhances comprehension and that its use will not necessarily reduce litigation.

Then there are those who believe it is wholly possible to communicate complex ideas and concepts in clear, unambiguous terms, without loss of legal consequence or status (Kimble 1994-1995).

Kimble (1992: 19-22) presents the criticism in the form of four myths:

- Myth 1: Proponents of plain language "[...] want first grade prose, or want to reduce writing to the lowest common denominator".

- Myth 2: Plain language does not allow any form of literary expression or effect. It does not recognise the ceremonial value of legal language.

- Myth 3: Plain language cannot replace legal language, as the latter contains many technical (specialist) terms.

- Myth 4: Plain language is not attainable as a goal, as the complex ideas that underpin the law require precision and accuracy.

Kimble (1992) then continues to refute each of these myths in the form of three realities:

- Reality 1: Legal language fails all tests, such as readability tests and comprehension tests. Moreover, readers prefer documents that are presented to them in plain language.

- Reality 2: Plain language saves time and money. Its use stimulates business and promotes competition. 
- Reality 3: The use of complex legal language results in a lack of respect for lawyers and the law.

\section{Approaching plain language in the consumer industry in South Africa}

In terms of section 64(2) of the NCA and section 22(2) of the CPA, consumer documents must be in plain language, to the extent that:

[...] an ordinary consumer of the class of persons for whom the notice, document or visual representation is intended, with average literacy skills and minimal experience as a consumer of the relevant goods or services, could be expected to understand the content, significance and import of the notice, document or visual representation without undue effort, having regard to -

(a) the context, comprehensiveness and consistency of the notice [...];

(b) the organisation, form and style of the notice [...];

(c) the vocabulary, usage and sentence structure of the notice [...]; and

(d) the use of any illustrations, examples, headings or other aids to reading and understanding.

Knight (2006:19), who was involved in the formulation of plain language definition observes:

As a declared right, section 64 [of the NCA and section 22 of the CPA] enjoys a protected status within the Act. Any attempt to contract out of it would be illegal, and consumers who act to enforce this right are protected from retribution by the lender.

Knight (2006:19) also puts the right to plain language in context:

[...] clarity has been declared to be a right, alongside the right to participate in the economy, the right not to be discriminated against when participating in the economy, the right to receive information, and the right to have legal rights protected.

Cornelius (2015: 9) analyses this definition in relation to international classifications of plain language definitions and concludes that "(T)he definition [...] displays characteristics of both elements-focused and outcomes-focused definition types [...]". She continues as follows:

The definition contains guidelines for readability and clarity in the form of a list of writing techniques and linguistic devices to be employed, but also suggests that testing could be an important consideration. [...] Empirical testing and statistical results can inform the guidelines according to which plain language practitioners should write or rewrite consumer documents for lay audiences. Testing can eliminate subjectivity and guesswork that may be inherent in the phrase "that an ordinary consumer [...] could be expected to understand".

According to the Plain Language Group of South Africa (2010: 2), South Africa takes the lead when it comes to plain language legislation and the local definition of plain language has been 
widely commended for its comprehensiveness. However, for consumers to be protected by these laws the Plain Language Group warned in 2010 that standards are needed to ensure compliance and enforcement by organisations and companies, and that "a common understanding of what plain language is" is of the utmost importance to avoid costly effects of approaching the plain language project from a precarious basis.

Knight (2006: 20) addresses the issue of standards and comes to two conclusions: an objective test (such as a readability formula) would allow for "technical compliance, but substantive evasion", and a subjective test (assessing compliance in terms of the actual ability of a specific consumer to understand a document, or the probability that a particular class of consumers is likely to understand) would mean that "(I)ndustry would never have any degree of certainty that it was complying with the law, and would always be exposed to an unacceptable degree of risk". What, then, is the route out of this apparent impasse?

The answer, according to Knight (2006: 21), lies in an imagined ordinary consumer, whose "ability to read and understand a document varies with two kinds of life experience": this consumer is a "somewhat experienced reader" and a "novice debtor". The court will thus have to determine "whether it is reasonably probable that a somewhat experienced reader, even though a novice debtor, who makes a reasonable effort to do so, will comprehend the document" (ibid). In addition, and in relation to the three nouns "content", "significance" and "import", the court should take into consideration the purpose of consumers in reading the credit agreements they enter into and whether they understand (i) what the document communicates; (ii) what the document has to do with the credit arrangements; and (iii) the effect of the document. Lastly, the court, or any person who wants to determine whether a document is in plain language, should also examine four textual features: whether (i) the thought "reflected in the document $[\ldots]$ is $[\ldots]$ complete, comprehensive and consistent"; (ii) the organisation and presentation is logical, (iii) attention has been given to vocabulary and sentence structure; and (4) aids to understanding have been used. Finally, Knight (2006: 21) concludes that the plain language rule "requires that the intended readers will probably be able to understand the document, and directs the court and others as to how to assess whether that test has been met".

Against this backdrop, and in order to achieve the overall aim of this study, it is necessary to determine, among others (i) how major banks in South Africa interpret the definition; (ii) the specific approach they follow to ensure compliance; and (iii) what yardsticks, if any, they use to determine whether a document is indeed in plain language.

\section{Methodology}

This qualitative study is directed by the following research question: Is it possible to make complex, legally binding bank documents available in plain language and if so, how can this be achieved? The ways in which three major South African banks approach the plain language directive are explored by focusing on three levels, from high level ideas to project in action in divisions within the institution: (i) macro processes and procedures on a regulatory level, relating to legislative requirements, compliance, and issues of interpretation, (ii) meso approaches on an institutional level, relating to policies, practices and workflow processes within the bank; and (iii) micro strategies on the language services level relating to specific editorial practices and translation issues. 


\subsection{Data collection}

This qualitative study constitutes a grounded theory study, as it is essentially data-driven (Henning 2004; Leedy and Ormrod 2005). This study thus attempts to develop theory, in the form of a model, by discussing and conceptualising the data. One of the methods of data collection in a grounded theory study is focus group interviews (Leedy and Ormrod 2005: 144). Indeed, Kitzinger (1994: 108) asserts that "(G)roup work is invaluable for grounded theory development".

The decision to use focus group interviews is based on the premise that focus groups do not "make statements about the population but provide insights about how people in the groups perceive a situation" (Krueger and Casey 2009: 66). In addition, focus groups are useful as "(I)nteraction among participants may be more informative than individually conducted interviews" (Leedy and Ormrod 2005: 146). Remenyi (2013: 57) refers to "multiple voices" being heard on a particular topic, providing a "richer understanding than even the most knowledgeable single voice". The researcher aimed to create conditions for a robust debate between group participants. This study aims to explore a topic, i.e. approaches to plain language in the banking sector, about which precious little is known.

The three focus group interviews were held on location; that is, in a boardroom on the premises of each of the three banks in question. Group discussions lasted on average one and a half hours.

\subsection{Composition of the focus groups}

According to Krueger and Casey (2009: 66) the composition of the focus group is "characterized by homogeneity, but with sufficient variation among participants to allow for contrasting opinions". Kitzinger (1995: 300) agrees:

Most researchers recommend aiming for homogeneity within each group in order to capitalise on people's shared experiences. However, it can also be advantageous to bring together a diverse group (for example, from a range of professions) to maximise exploration of different perspectives within a group setting.

In this study, a total of three focus groups were created, each group consisting of "clusters of people who already knew each other through [...] working [...] together" (Kitzinger 1994: 105) on the plain language project in the three banks. These groups can be regarded as "naturally occurring" (Kitzinger 1995: 300) groups, as these people work together in a single institution. In order to investigate the research problem from two angles - from the perspective of legal and language practitioners - representatives from both language services units and legal divisions participated. This would "allow for contrasting opinions", as envisaged by Krueger and Casey (2009: 66), and would ensure that the plain language project is viewed from at least two different vantage points.

In the case of Bank B, representatives from the legal division initially agreed to participate, but cancelled as they did not feel comfortable to participate in the focus group discussion. However, this division offered to respond, in writing, to the questions outside of the focus group interview. The interview questions were sent to a representative of this division electronically and a 
unified response - representing the viewpoints of the legal division - to all the questions was returned, also electronically. These responses were incorporated in the data analysis.

In the case of Bank $C$, representatives from the legal division were not available, for an unknown reason, when the focus group discussion took place. They initially accepted the invitation to participate, but cancelled on the day the focus group discussion was scheduled to take place. In this case, an employee from the documents section of the bank, who was, and still is, intricately involved in the plain language project, participated and was able to speak for the legal division, to a certain extent. This is not ideal, and could be seen as a limitation of the study. However, the researcher has little control over who the banks allow to participate in a research study.

In both cases, the apparent reluctance to participate occurred in the legal divisions of the banks, not in the language services units, which could be interpreted in different ways: (i) it may simply be a case of representatives genuinely not being available as other more serious work required attention; (ii) this disinclination to participate, after demonstrating initial interest, may point to an awareness of potential compliance problems; (iii) they have been instructed by higher powers not to participate, when word of the focus group interviews got out; or (iv) in the case of Bank B, they preferred to provide unified and carefully considered (not spontaneous) responses as a group, not as individuals.

The three banks that participated were included in this study as they have language services units. Banks who do not have language services units were excluded from the current study; however, in a follow-up study these banks could also be approached to find out how they carried out the plain language project in the absence of a dedicated language services unit.

Due to the relatively small number of participants in each case (no less than three, but no more than four participants per group), the groups can be regarded as "small focus groups, or minifocus groups", with the advantage that "the smaller groups are easier to recruit and host and are more comfortable for participants" (Krueger and Casey 2009: 67). A total of 10 participants contributed to the discussions.

Each participant signed an informed consent form, in which issues of confidentiality and anonymity were dealt with, and completed a short biographical questionnaire, eliciting information such as position in the bank, length of employment in the bank, age, highest qualification, etc.

\subsection{Procedure}

The researcher first explained the purpose of the study and made it pertinently clear that the purpose of the study is not to check for compliance. She also explained issues relating to confidentiality and anonymity, after which she made available the consent forms for participants to read and sign. The researcher subsequently introduced the topic, starting off with (a) general, 'open-ended 'grand tour' question(s) that seek to obtain participants' overall orientation toward (the) topic" (Stewart, Shamdasani and Rook 2007: 114) and then moving on to more specific questions as, according to Gill, Stewart, Treasure and Chadwick (2008: 293) "(Q)uestions should move from general to more specific questions". 
The first question relates to perceptions in each bank towards the plain language project. Although the purpose of this question was to introduce the topic, to break the ice and to put participants at ease, responses are of extreme importance for the purpose of this study and the research question. Interviewees were asked to write down their responses to this question. The rationale for this was to get responses from all interviewees, not only those who took a conversational turn.

The researcher then proceeded by following a schedule consisting of a set of some 15 questions (see the interview schedule in the appendix), on three levels - from macro level to micro level - gradually moving from high-level ideas and interpretations to project in action, as already mentioned. This framework is also used for the purposes of data analysis.

- On the macro level: Topics were introduced to elicit responses pertaining to processes and procedures to ensure compliance with the plain language provision in the NCA and CPA. Such questions would revolve around the bank's interpretation of the plain language provisions/definition in the two acts, whether the bank has a language policy and/or a plain language policy in place, management of the project and compliance issues, etc.

- On the meso level: Here the discussion would focus on choices flowing from the bank's interpretation of the plain language provision and definition. Topics on this level include information regarding training and recruitment of employees to apply plain language, workload and use of resources, insourcing and outsourcing, relationships between divisions or units involved in the project, etc.

- On the micro level: Topics centred around specific editorial practices and translation issues. It is important to ascertain whether the banks in question have a plain language style guide in place, thereby (i) providing guidance to those involved in the actual drafting or rewriting of bank documents in plain language; and (ii) ensuring consistency in the bank's documents.

All three focus group discussions were audio recorded and subsequently transcribed.

As mentioned earlier in this paper, this study aims to explore a topic about which little is known. Stewart et al. (2007: 109) note the following: "For such exploratory research, a simple descriptive narrative is quite appropriate and often all that is necessary". In analysing the data, the "scissor-and-sort-technique" (Stewart et al. 2007: 116) was followed. Although the researcher followed a schedule, introducing one question or topic at a time, the focus group participants tended to revisit earlier topics at later stages during the interviews, for instance when they remembered something of importance later on.

The researcher thus found this technique very useful. It entailed working through the transcripts and coding information related to different topics or questions, by using the framework for analysis outlined above. Following the coding process, the data were rearranged according to the framework for data analysis, so that information relevant to a particular topic was placed together, according to the three levels (macro, meso and micro) discussed above.

In the section below, the interpretative analysis follows. To ensure confidentiality, banks' identities are withheld; instead banks are referred to as Bank A, Bank B and Bank C. 


\section{Analysis and discussion of the data}

\subsection{Responses to the "grand tour" question}

As mentioned, in each case, the focus group interview was initiated with a general question. This question asked the following, to which interviewees responded in writing: "To what extent do you think bank documents can be successfully produced in plain language for the ordinary person to understand without much effort?" This question was followed with: "Has this always been your view? Or have you changed your view somewhere along the line?"

In general, all participants, both legal and language practitioners, agree that applying plain language is possible, but not without:

- incurring relatively high cost;

- much effort;

- close collaboration between different role-players in the institution;

- uniform interpretation and set guidelines;

- $\quad$ taking into consideration the varied target audiences of bank documents;

- a solid grasp of the contents of the document;

- $\quad$ ensuring that the legal status of a document is not compromised; and

- managing risks.

Both the legal and language practitioners from Bank B provided nuanced and qualified responses. One of the interviewees (a language practitioner) from the language services unit responded as follows: "I do not think all legal contracts can be simplified and still be risk-free as far as legal enforceability is concerned. Some simplification is however possible". Another language practitioner mentioned that, in very complex legal contracts, intervention may be limited to cosmetic changes only. The legal practitioner agreed by mentioning that marketing and product material can be produced in accessible and understandable language, but in legally binding documents there is potential for prejudicing the consumer and the bank. Bank C's language practitioners intimated that legal practitioners in the bank often hide behind the idea that legal documents have to be legally binding and thus they are not always convinced plain language is an option.

In response to the follow-up question, interviewees from all banks who were initially against the idea of plain language, changed their views after increased exposure to and practice in plain language principles. A language practitioner from Bank A mentioned that she always thought "legal is legal" and that "old habits die hard", referring to the more traditional styles of legal drafting, but that she is now convinced that some simplification is possible. Thus, either interviewees were always convinced that the use of plain language is possible in bank documents, or those who were initially sceptical, became more accepting of its merits after experiencing positive results. However, interviewees across all banks agree there is always a need to carefully manage potential risks. 


\subsection{Data collected on the macro level}

Four questions relate to regulatory issues on the macro, institutional level.

\subsubsection{Familiarity with and interpretation of the plain language provision}

The researcher introduced a set of related questions pertaining to the plain language provision in both acts: "How familiar are you with the plain language provision in the NCA and the CPA? What guidance did you get from that provision, if any?"

Interviewees from all three banks indicated that, whenever a new law is passed, legal advisors within each bank will produce a position paper. One legal practitioner from Bank A explained that the bank would arrive at a single interpretation of a particular section and come up with action plans for implementation. In the case of Bank A, for instance, all stakeholders in the bank would be informed of the bank's interpretation of a particular section. In this case, this position paper would then constitute the official plain language policy of Bank A.

Across the board, interviewees pointed out that they are familiar with the provision, but that little guidance is provided in the provision. This vacuum results in two important consequences: (i) banks are willing to take risks, as there is no indication of enforcement measures or penalties; and (ii) adaptation of bank documents for lay consumption boils down to guesswork about what plain language is, when a document can be regarded to be in plain language, what "undue effort" is, and so on. One of the legal practitioners (incidentally from Bank A) mentioned that he looked at a legal document and asked a colleague why this particular document is not in plain language, upon which the colleague replied that it is in plain language and that he is indeed looking at the plain language version.

It thus seems that the banks' position papers are therefore not really helpful to those employees working in different divisions in the bank. Again, in the case of Bank A, a language practitioner noted that the problem with the plain language provision is that there are no criteria available to measure documents for compliance. In the legal section alone, there are approximately 40 people who can, potentially, each have their own interpretation of what plain language is. This, again, indicates that the bank's position paper is not helpful.

This problem occurs in all three banks. Language practitioners from Bank B mentioned it would be possible to tick all the boxes in relation to compliance with the NCA and CPA (they have all the required clauses in their contracts, they explain everything that needs to be explained, and the customer needs to agree to and sign all confirmations). Yet, a degree of windowdressing seems to remain, as "anyone with a modest degree of creativity can assemble simple words in short, direct sentences that nevertheless obscure meaning (Knight 2006: 20).

Knight (2006: 19) advises industry as follows:

(f)irst [...] consider the scope of application of the [relevant] Act, both as to the transactions to which it applies, the borrowers who are protected by it, and the documents that are required to meet the 'plain language' standard. 
Position papers should provide guidance for easy implementation and interpretations should be such that they give effect to the spirit of the plain language provision.

During all three focus group interviews, mention was made of a new regulatory approach in banks, known as the TCF (Treating Customers Fairly) doctrine to which banks subscribe. This means the National Credit Regulator (NCR) will consider market conduct at every level of dealings within the bank. There are six outcomes of the TCF policy and one of these is to make sure customers know what they are getting themselves into.

Banks, according to one of the interviewees (a legal practitioner from Bank A), have to test themselves against that principle at all times in everything it does, including making understandable agreements available. Such a philosophy moves beyond legislation and interpretation of wording; it is wider than the use of language only. A manager of language services in Bank B mentioned that they do not pay attention to the two acts (NCA and CPA) in isolation, as this would amount to window-dressing. There is a need to work wider than what legislation requires of banks. All interviewees agreed that the plain language provision in the NCA and CPA neatly dovetails with the TCF.

\subsubsection{Compliance and testing}

In response to the question "Do you test your plain language documents on real readers at all?", interviewees from all banks indicated that they do not test any of their bank documents on consumers and that they do not have standards or measures in place to ensure compliance. One of the legal practitioners from Bank A mentioned that, during drafting of agreements for instance, he tests the document on himself by assuming the role of the reader. A language practitioner from the same bank warned against this, as a drafter with legal training and experience, and domain knowledge, is never really able to put himself in the shoes of a vulnerable consumer; moreover, such a person is a sophisticated reader of the type of document concerned and, as such, can never be a reader with "minimal experience as a consumer of the relevant goods or services". Interviewees from Bank C noted that reviews of all standard legal documents are carried out every two years, but this does not involve testing on real consumers.

Testing can be a helpful tool where vagueness creates problems. As mentioned earlier, Cornelius (2015: 9) suggests that testing can "eliminate subjectivity and guesswork that may be inherent in the phrase "that an ordinary consumer [...] could be expected to understand". Despite Knight's (2006) reservations about testing (cf. section 3), small-scale testing of documents on real readers can be very meaningful and does not have to be a costly endeavour, as Schriver (1991: 155) suggests "[...] even one protocol is better than no protocol [...]". The results of a small-scale test can inform subsequent revisions to a document.

\subsubsection{Language policy}

The question "Does your bank have a language policy?" was specifically introduced to find out how banks deal with the fact that the plain language provision in the NCA and CPA ignores the linguistic landscape in South Africa, and provides no guidance on how multilingualism and multiculturalism should be dealt with in the consumer industry. 
What transpired during the focus group interviews, and which is critical for this study (more important than a general question about language policy), is that banks must enter into agreements with the NCR in terms of the languages they select for use in credit agreements. All three banks have such agreements in place, undertaking to make available credit agreements in two official languages. In all cases these two languages are English and Afrikaans.

Abridged, and simplified, versions of such agreements are made available in an additional three (in the case of Bank A, four) indigenous languages. However, these abridged versions are not legally binding and for information purposes only, as the customer does not sign such a version. One of the language practitioners from Bank B mentioned that this is an attempt to work around the gap in the plain language provision (that is, that the multilingual and multicultural South African landscape is not acknowledged).

Although this attempt to address the gap in the plain language provision is commendable in some sense, an important corollary of limiting the use of the indigenous languages to abridged credit agreements without legal status, is that the indigenous languages are relegated to the background, their status is diminished and so it further perpetuates what Kahn (2001:3) warned against: "The black languages are virtually non-existent in law and commerce". ${ }^{1}$ Although a vulnerable consumer is provided with an abridged, and possibly more accessible, credit agreement in an indigenous language, the consumer still has to sign a full agreement in a language $\mathrm{s} /$ he does not necessarily understand (English or Afrikaans).

\subsubsection{Legality of and signing of documents}

These topics were introduced by asking two questions: "How do you ensure that the legality of documents is not compromised by the use of plain language?" and "Describe the processes, if any, that are in place to ensure that legal documents are checked and signed off, after they have been revised for plain language."

In all three cases there are strict procedures in place for signing off documents to ensure that the legality of documents is not jeopardised as a result of any simplification attempts. Documents are usually signed off by a number of different divisions within a bank, such as compliance, credit, business, legal and language services.

Strict measures are in place in Bank A, whereby the following business units sign off on a document: compliance, credit, business and legal. The responsibility does not lie with one single unit or person, such as language services. This is in line with banks' predilection to avoid risk of any nature whatsoever, including any potential risk that might arise due to the use of accessible language.

\subsection{Data collected on the meso level}

\subsubsection{Location of language services in the institution}

Responses to the question "Where is the language services unit located in the bank?" revealed that the language services unit is either in a unit typically referred to as marketing and

\footnotetext{
${ }^{1}$ The author of this article does not agree with Kahn's (2001) use of the term "black languages".
} 
communication (in Banks $\mathrm{A}$ and $\mathrm{C}$ ) or, as in the case of Bank $\mathrm{B}$, in the compliance unit. Interviewees from Bank B noted that the issue of plain language is a compliance issue in terms of the NCA and CPA. During the interviews, it became clear that the language services unit has more authority if it is placed in the compliance unit, as they "can raise the risk" (the words of a language practitioner). This echoes a recent finding by De Scally (2015: 71) in relation to corporate language offices, such as government departments, banks and statutory bodies: "Reporting to a client impacts on credibility and is not best practice."

An interviewee from Bank C's language services unit said after translation or editing, business units can bring about any change in a document, and this directly relates to the relative position of the unit in the larger organisation (i.e. if the language services unit is not located in the unit responsible for compliance). An additional, but related, problem is that employees in the marketing and communication unit, under which languages services in Bank B resort, think that language services work for them and that their work should always receive priority (this is also in line with the finding of De Scally 2015).

A language practitioner from Bank A also agreed that the issue of location within the bank has important consequences, in the sense that it is not clear who takes responsibility to drive the plain language project in the bank (in her words: "It is all very confusing."). One of the legal practitioners agreed by saying: "If the bank's documents are not in order, compliance regulatory services must take the fall."

\subsubsection{Approaches to the plain language provision}

This topic was introduced by explaining to interviewees three possible approaches to the plain language provision in the NCA and CPA: formula-based, elements-focused or outcomesfocused (Cheek 2010, Cornelius 2015). Interviewees were asked the following questions: "Which approach, or combination of approaches, did/do you follow in relation to the plain language provision in the two acts? Or did you follow a different approach altogether?"

Responses revealed that none of the banks follow a formula-based approach (for instance, subjecting their documents to readability formulas). Bank A's language practitioner mentioned that the bank follows an elements-focused approach. Language practitioners from Banks B and $\mathrm{C}$ are of the opinion that they follow a combination of elements-based and outcomes-focused approaches. They thus follow writing guidelines (typical of an elements-based approach), but at the same time they consider the potential target reader (typical of an outcomes-focused approach), according to the type of document concerned.

\subsubsection{Prioritising documents}

Responses to the questions: "How do you arrive at decisions about which documents to deal with first? How do you prioritise, as the bank surely has a great number of documents on its books?", revealed that client-facing documents and marketing material are singled out for plain language intervention. An agreement between the bank and another company, for example, does not require the use of plain language. The same holds true for documents in the business and wealth units. Interviewees from all three banks indicated that they experience problems with heterogeneous readerships, even within a single category of documents, for example client-facing documents. 
However, a description of particular information, provided by interviewees, regarding banks' approaches to different types of documents is needed in order to provide a complete picture of how documents are prioritised and in which cases use of plain language is regarded a priority.

In Bank A, there are two kinds of credit or transactional agreements:

- First, there are templates that are stored on the bank's system. These documents were revised some eight years ago, in order to comply with the plain language provision, when the NCA came into force. Subsequently, whenever legislation changes, only the relevant clauses that are affected by these legislative changes are revisited. One of the legal practitioners noted that plain language in these templates "died a slow death", as what was done some years ago remains, and in response to legislation changes only particular clauses are revised, when and where needed. Additionally, many different people work on the same document over an extended period of time.

- Second, there is the case of bespoke agreements. These are agreements that are drafted and tailored for specific purposes, usually in the presence of the customer. In these cases, plain language is right at the bottom of the priority list, as a result of quick turnaround times and other pressures.

The legal practitioners highlighted the problems they experience with different types of readerships and different types of legal documents, and the mind shift this requires of those involved in document drafting. Interviewees mentioned that plain language is no longer something that Bank A actively focuses on, except for SMSs, flyers and advertisements.

Interviewees from Bank B indicated that they do not use plain language in any legal agreements, due to the potential risks to the bank. However, they use plain and understandable language in explanatory statements that, as mentioned, are not legally binding. The legal practitioner mentioned that client-facing documents and marketing material are a priority.

Bank $\mathrm{C}$ focuses on all standard legal agreements (i.e. the terms and conditions of all their products). They recently embarked on a comprehensive simplification and consolidation project, resulting in a reduction from approximately 900 to around 400 bank documents. Interviewees alluded to the huge successes of this project.

From the above, it is clear that banks experience problems with the two-audience, or multiaudience, dilemma (Gibbons 2003: 174): the difficulty of writing for competing audiences. Such difficulties in deciding which audience to write for is ever present in South Africa, a problem compounded by a population that is characterised by wide-ranging literacy rates. Therefore, it is important for banks to categorise their documents according to potential target readerships and potential risk, and to focus on client-facing documents that have "an ordinary consumer of the class of persons for whom the notice, document or visual representation is intended, with average literacy skills and minimal experience as a consumer" as their primary readership.

This is echoed by Sullivan (2001: 108) when she suggested that such ordinary citizens are typically not members of the legal profession who have "above average intelligence and 
sophisticated reading skills; its members [those of the legal profession] are highly educated and unusually well-informed".

\subsubsection{Cooperation between divisions in the bank}

Interviewees were asked: "Describe the relationship between different divisions and roleplayers involved in the plain language project in your bank." Reponses point to high levels of cooperation in all three banks, specifically between legal and language units, but also with compliance officers in the banks. One of the language practitioners from Bank B works closely with two legal practitioners on the drafting of the explanatory statements this bank makes available in the indigenous languages. The legal practitioners are acutely aware of issues that may become problems with the ombud and the NCR, and therefore, such cooperation is crucially important. Interviewees representing Bank $\mathrm{C}$ mentioned that all role-players are viewed as experts in their field and, as such, they contribute specialised knowledge and skills to the plain language project.

\subsubsection{Availability and use of resources}

\section{(i) Human resources and workflow}

Responses to the question "Who does the actual plain language work in your bank?" revealed that varied practices are followed.

At Bank A plain language work is outsourced, as is translation into the indigenous languages. However, translation and editing work in English and Afrikaans is done in-house. At Bank B, explanatory statements are drafted in-house by one of the language practitioners (in collaboration with two legal practitioners). Outsourcing of this function was considered at some point in the past, but decided against. Translation into the indigenous languages is outsourced.

The Afrikaans and English language combination is dealt with in the language services unit. Legal practitioners of Bank $\mathrm{C}$ do all plain language work. Translation is the responsibility of the language services unit, who is able to deal with Afrikaans, English and Sotho in-house. However, as agreed with the NCR, translation into the indigenous languages is currently on hold (involvement of the language services unit is limited to translation of bank documents into Afrikaans only), but if customers request to have a document in a particular language, they will be assisted in their language of choice.

Interviewees across the board described outsourcing as a difficult and complex process, as quality is most often compromised. It is necessary to check the quality of freelancers' work, a problem that is exacerbated by limited time and human resources. Consistency problems are prevalent as a result of outsourcing.

Workload and cost

As far as the question "How did the plain language project impact your workload?" is concerned, interviewees all agreed that the impact on workload is substantial, and that workload more than doubled since the inception of the NCA some 10 years ago. Interviewees from all 
three banks also indicated that the demand for plain language by far exceeds translation demands.

When asked the question "How costly is the project?", interviewees from Bank A noted that outsourcing runs into millions of rand. Bank B language practitioners also noted high cost, but intimated that they are not convinced the project was cost-effective, as resources were wasted on practices that were not sensibly and sustainably conceptualised and executed. However, according to the legal practitioner, additional cost and effort ultimately benefit the banks' customers and therefore these costs are justified. Bank $\mathrm{C}$ interviewees warned that "business as usual" suffers as a result of the use of in-house resources (both human and financial) for plain language and simplification projects.

Training

The researcher introduced the topic of training by asking: "Do employees in the language services unit and legal division receive training in the principles of plain language and are they equipped to do plain language work?"

Employees received, and continue receiving, very limited, if any, training in plain language principles or drafting of bank documents for ordinary consumers. There is a serious need for in-depth training and continued professional development. Training to date has been mostly limited to short workshops of no longer than two days at a time.

One of the legal practitioners employed by Bank A stated that there are a number of legal practitioners working at the bank who have never received any training whatsoever and incoming (new) employees are also untrained. The language practitioners representing Bank B lamented the fact that, in general, very few language practitioners are trained and adequately equipped to work in the financial services industry and thus there are not enough newly trained language practitioners entering the job market.

This problem is further exacerbated by employment equity requirements. Some years ago both legal and language practitioners from Bank B attended a training course, offered by the Law Society, but the legal practitioners walked out as the training was of very poor quality and the content not credible. In the case of Bank C, expertise was brought in from the United Kingdom (UK). Employees are not formally trained but they learn, by way of modelling, from these experts from the UK.

\subsubsection{Perceptions in the bank}

\section{(i) Perceptions about the concept 'plain language'}

Interviewees were asked "What is the general perception in your institution about plain language: Are people positive or negative towards the notion of plain language?" Interviewees in general indicated that banks are mostly positive towards the concept and the underlying philosophy and spirit of the plain language provisions in the NCA and CPA.

However, according to the legal practitioners from Bank A, the challenge rather lies in the varied perceptions people have of what plain language is. This lack of a uniform interpretation 
of the concept 'plain language' poses a bigger problem than people's acceptance of the need to make legal documents easier to understand by ordinary customers. In Bank B, the language practitioners referred to a perception among legal practitioners in the bank that the use of plain language dilutes the legal status of a document. The legal practitioner, in turn, agreed that documents can only be simplified if there is no concomitant loss of legal meaning and if the legal status of a document remains intact.

It thus seems that, although banks are positive about the need to use plain language, there is little consensus about (i) the concept 'plain language', and (ii) the degree of simplification required, and consequential legal issues and risks.

\section{(ii) Perceptions about success/failure of the plain language project}

In response to the question: "Do you believe the plain language project in your institution was/is a success or a failure?" responses were varied.

Interviewees from two banks (Banks A and B) explicitly noted that banks are "getting away" due to the lack of enforcement. Bank C's interviewees described the plain language project as a huge success.

One of the legal practitioners from Bank A provided a somewhat peculiar measure of success, by responding as follows: "Well, we haven't been fined yet." ${ }^{2}$ Viewed in this way, it means not having been fined equals success. However, he noted that a much better test would be the TCF doctrine, referred to earlier. According to a language practitioner from Bank B, banks limit their risks and deal with problems on an exception basis. This language practitioner mentioned banks can afford to do so, as in South Africa "banks operate in a market where consumers do not take them to court". Bank C interviewees described the current simplification project at the bank as a huge success, in that it facilitates translation, particularly into the indigenous languages. They also agree, as in the case of Bank A, that the bank's brand and image are in danger if customers receive documents that they cannot understand. Following the simplification drive, bank employees noticed a marked reduction of administration tasks as a direct result.

Stumbling blocks that hamper the success of the plain language project include the following:

- Documents are not revisited continuously; only when legislation changes. This results in a disorganised approach to plain language and lack of consistency in bank documents.

- Lack of planning, coordination, sound project management and centralisation leads to wasteful expenditure and other consequences (for instance, translations into indigenous languages are not updated when legislation changes and they are not offered to customers by branch employees, resulting in low uptake in these languages). A number of these problems relate to the location of the language services unit in a division other than compliance.

\footnotetext{
${ }^{2}$ This may not be entirely true. Interviewees from another bank mentioned that this particular bank has indeed been taken to court on the basis of a poorly drafted contract, but the details of this case will not be divulged in this article as it will compromise the anonymity of this bank.
} 
- The outsource model does not work well, as quality assurance problems are pervasive and checking freelancers' output is time-consuming, and often there are not sufficient human resources available for this task.

- Legal practitioners' fear of risk result in cosmetic interventions and window-dressing.

\subsection{Data collected on the micro level}

Data collected on the micro level mainly relate to consistency issues, ensuring that uniform editorial decisions on text level are made by all those involved in the plain language project. Two issues are considered on this level: (i) whether banks have, and follow, a dedicated plain language style guide; and (ii) what quality assurance procedures are in place.

\subsubsection{Plain language style guide}

The question "Does your bank have a plain language style guide or checklist?" revealed the following: One bank (Bank A) has two versions of a plain language style guide, whereas the other two banks do not have a plain language style guide. However, of note, is that both the legal and language practitioners from Bank A believed, at the time of the interview, that the bank does not have a plain language style guide.

A week after the interview, one of the legal practitioners informed the researcher that he obtained two different style guides, outlining plain language principles and dealing with interpretation issues. However, it is telling that none of the interviewees, at the time of the focus group interview, knew of the existence of these documents. As mentioned, Bank B does not make legal agreements available in plain language as it increases risk and therefore they do not have a style guide specifically dedicated to plain language. They have a general style guide, setting out editing principles to be followed in all bank documents. They also, on a very superficial level, edit for increased understanding, for instance by removing "shall”, by opting for active voice, by avoiding excessive use of capital letters, and so forth. Bank $\mathrm{C}$ also has no style guide for plain language, although they have a fairly vague general style guide.

For translation and editing, style manuals and guides are important as, according to Mossop (2007: 39), they "help create a distinctive institutional voice [...] and create consistency among all the texts" produced by a bank. The absence of a style guide for plain language is detrimental to consistency. Uniform approaches within an institution to plain language, grounded in research on text processing and comprehension, are critically important to ensure the success of the project.

A well conceptualised and comprehensive plain language style guide can, therefore, go a long way to alleviate some of the problems that are created by the vagueness practitioners experience in the plain language provision in the NCA and CPA, and can reduce the amount of guesswork that practitioners - both language and legal - resort to in order to comply with these acts. In addition, the existence of a plain language style guide could also provide evidence of the bank's diligence, and its commitment to the use of the understandable language, if ever a dispute arises or a complaint is lodged.

In the case of all three banks, document length is an important issue. Banks want to keep documents short, as they work from the assumption that customers are more inclined to read 
shorter documents, and printing costs are thereby reduced. On the other hand, it is by now accepted that plain language documents are often longer than the original documents they are based on, as more clarification is required and examples are often provided to render content less abstract (Cornelius 2012: 271). However, (longer) plain language documents are easier to process and to translate, and less reading time is required due to the less dense packaging of information. The reputational risk a bank is likely to suffer as a result of shorter (but more difficult to understand) documents can be higher than the printing cost of longer (but easier to understand) documents. Banks need to weigh up the arguments for and against document length carefully.

\subsubsection{Consistency of choices and quality assurance}

The last question was "How do you ensure consistency (of approach and choices) among all practitioners working on the project?" All three banks rely heavily on outsourcing of different services, from plain language to translation (particularly into the indigenous languages). However, in all cases, interviewees noted a number of problems that outsourcing creates, mostly relating to mistakes and consistency issues. These problems place a burden on in-house practitioners who are already overworked - ironically, the primary reason for outsourcing in the first place.

According to a language practitioner from Bank A, different agencies or contractors follow different approaches. A single standard clause may occur in more than one agreement, yet it is treated differently by freelancers working for those agencies or contractors. Even though the bank's general style sheet is provided to outside agencies or contractors, the style sheet is not specific enough to ensure consistency for plain language revision.

Although Bank B does not revise their documents for plain language, as already noted, the explanatory statements they make available are drafted in-house, as outsourcing poses huge risks to the legal status of bank agreements. Translation into the indigenous languages is outsourced to the same agency which goes to great lengths to ensure that the same translator works on the same document or set of documents. This practice, according to interviewees, is effective.

Bank C's plain language work is done by legal practitioners within the bank, and as translation into the indigenous languages has been suspended, except when a particular request is received, consistency and quality assurance problems are limited.

\section{Recommendation: a proposed model for plain language in the banking sector}

The findings reported in this article are used to inform a proposed model for plain language in the banking sector. The model suggests ideal and conducive conditions, procedures, approaches and practices that should be in place to ensure effective and successful implementation of the plain language project and to give effect to the spirit of the plain language obligations in the NCA and CPA. This model may also apply in other sectors or institutions, possibly with minor adaptation, where required. Below is a schematic representation of the model, followed by a discussion of each of its modules. 


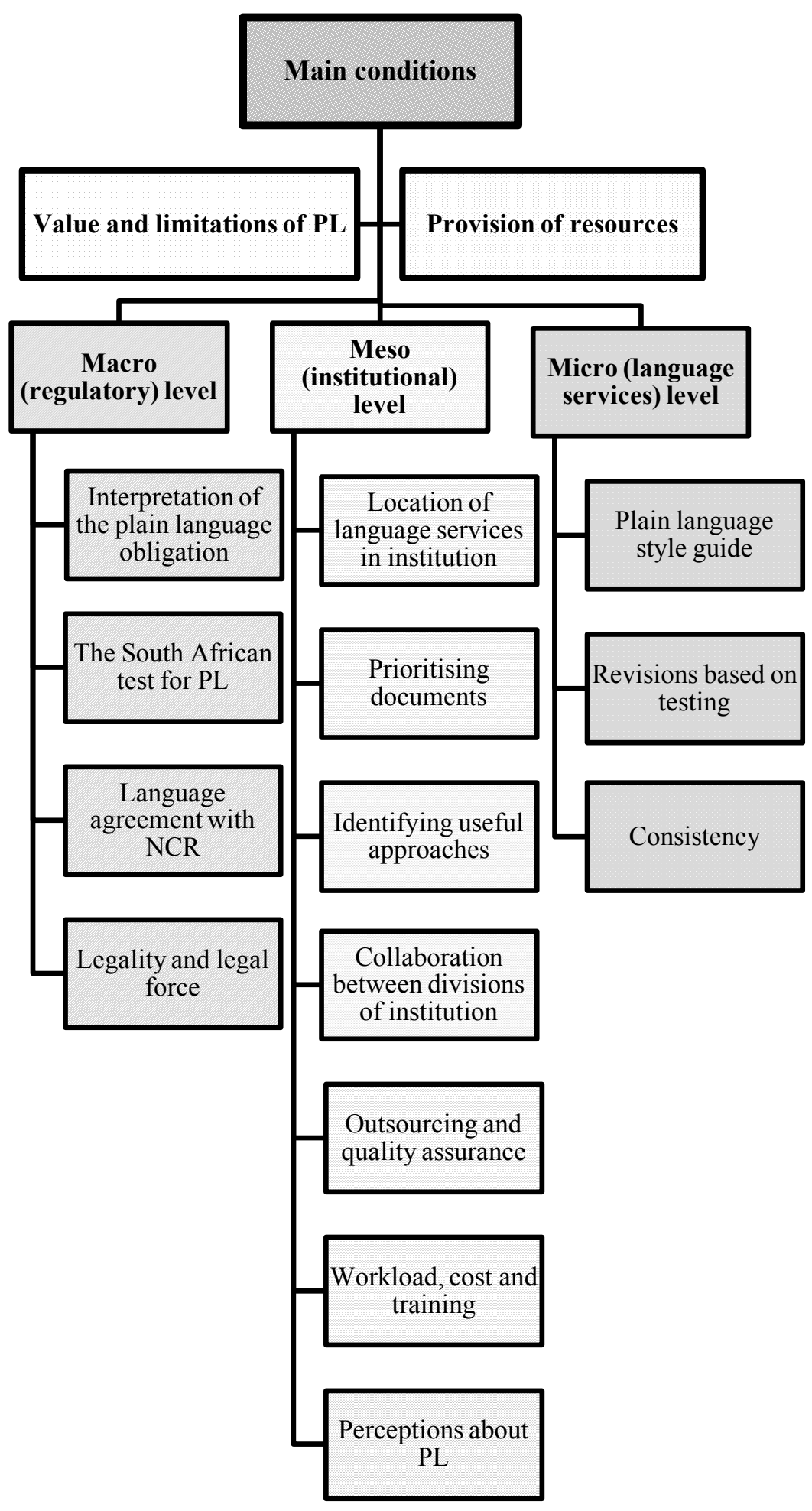

\subsection{Two main criteria}

The model consists of two main criteria that should be met as prerequisites for success:

Acceptance of the value and limitations of plain language. Those in management positions must subscribe to the philosophy underlying the use of plain language, and therefore, it is important 
that they fully understand the requirements of the obligation, as embodied in the NCA and CPA. Top-down support is crucially important to ensure success; support that filters down to the lower echelons in the institution. Decision-makers in the institution must, among others, recognise the protection plain language affords vulnerable consumers and thus its relation to customer care and other doctrines such as the TCF. At the same time, they should appreciate that a combination of specialised linguistic and legal knowledge and skills are required to make complex content accessible to ordinary consumers. This leads to the second main criterion.

Provision of sufficient human and financial resources. Since the inception of the NCA, some 10 years ago, plain language demands in specifically the banking sector exceed, by far, demands for other language services such as translation and editing. Plain language work require collaboration between different divisions. Decision-makers in the institution must ensure that both the legal and language units are sufficiently resourced to cope with the shift in demand towards plain language work.

\subsection{The macro level}

On the regulatory level the following considerations should be taken into account:

Interpretation of the plain language obligation. The intent of the legislator, as outlined in Knight (2006), should be reflected in institutions' position papers, which in turn should provide practical guidance to the lower levels of the institution (those who actually have to do the work). To facilitate the plain language project, considering the specifics of the language requirements, which according to Knight (2006: 19), "are illustrative of only one of the many options available when pursuing the goal of clarity in legal texts".

The South African test for plain language. It would benefit institutions to take heed of the article by Knight (2006), who provides background information that could assist in determining what a court would consider when it conducts an enquiry into the language used in credit agreements. Knight (2006: 21) warns that documents should not be seen as static artefacts; the "interpersonal dynamic of written human communication" should be the focus. In summary, the plain language provision gives guidance to the court (Knight 2006: 20-21):

- To imagine the reader of a credit agreement as "an ordinary consumer of the class of persons for whom the subject document was intended".

- To consider "whether it is reasonably probable that a somewhat experienced reader, even though a novice debtor, who makes a reasonable effort to do so will comprehend the document".

- To take the purposes into account for which the ordinary consumer will read the credit agreement, "asking whether it is probable that the consumer could understand the content, significance and import of the document".

Language agreement with NCR. When concluding agreements with the NCR, it is necessary to also consider the potential pitfalls of making available abridged versions of credit agreements - without any legal force - in one language, but requesting vulnerable consumers to sign the agreement in another language. Little protection is afforded if consumers still have to sign a legally binding version of a full credit agreement in a language they do not (fully) understand. 
Legality and legal force. Institutions should have strict procedures in place to ensure that the legality of the plain language versions of credit agreements is not compromised. This entails having signing off procedures in place whereby all relevant divisions within the institution indicate their satisfaction with the legality of the document. This is particularly important where plain language work is outsourced to agencies and contractors outside the institution.

\subsection{The meso level}

On the institutional level, considerations include the following:

Location of language services in the institution. The position of the language services unit in the institution can have a marked impact on the success of the plain language project. As the use of clear and understandable language in consumer documents, particularly credit agreements, is a regulatory requirement, it is best practice to locate language services in the compliance unit of the institution. This position will afford language services a higher status ("give them teeth") in the institution and will ensure better management and coordination of the plain language project.

Prioritising documents. In deciding which documents to prioritise for plain language intervention, it is imperative that an institution should revisit the intent of the legislator as described in 6.2 above and to keep in mind that documents should be categorised according to their potential target readerships. Documents with "an ordinary consumer of the class of persons for whom the subject document [is] intended", Knight (2006: 20) argues that the target reader should be given precedence. This consumer is not someone who cannot read; it is a person with average literacy skills: "a test that can, and should, be applied in a flexible manner, having regard to the various patterns of literacy in various localities and across various economic classes" (ibid). Additionally, such a consumer is not an experienced borrower.

This means that documents intended for sophisticated readers and consumers (such as business and wealth clients) do not require plain language intervention in the documents they use. Documents need to be revisited at regular intervals, and not only particular clauses that require amendment when legislation changes.

Identifying useful approaches to the plain language project. Based on the findings of this study, a combination of elements-based and outcomes-focused approaches would serve to best reflect the intent of the plain language provision. The plain language provision indeed consists of two parts. It provides:

- a profile of the ordinary consumer, having two kinds of life experience (as a reader and a borrower) and a particular purpose in reading the document concerned (this is characteristic of an outcomes-focused approach); and

- a list of textual features (this is characteristic of an elements-based approach).

Collaboration between divisions of the institution. The success of the plain language project strongly hinges on the extent of collaboration between specifically the language services unit and the legal division. However, there needs to be an acceptance of and consensus about (i) which documents to prioritise; and (ii) the degree of simplification required. Language 
practitioners contribute specialised (psycho-)linguistic knowledge of how "meaning [...] is created in the minds of readers applying themselves to a document and the symbols encoded upon it" (Knight 2006: 20-21), whereas legal practitioners bring knowledge of the law and regulatory requirements to the table. This kind of collaboration makes it possible to render legal documents in plain language for lay consumption.

Outsourcing and quality assurance. Outsourcing of plain language work should be avoided as far as possible. Capacity should be built within the institution, with outsourcing limited mainly to translation services.

Workload, cost and training. Decision-makers in institutions should be aware of the increased workload and cost related to the plain language project and sufficient resources should be made available, as outlined in section 6.1 (under Provision of sufficient human and financial resources). It has been pointed out in section 6.1 that this is one of the main criteria to ensure the success of the project. Ongoing, good-quality training should be provided to employees in all divisions of the institution, who are involved in the plain language project.

Perceptions about plain language. Although positive perceptions about plain language seem to prevail in the three major banks that participated in this study, negative or ambivalent perceptions can be changed if more local research is conducted to determine the real benefits of the use of plain language. Financial benefits as a result of increased understanding of consumer documents and consumer satisfaction will go a long way to change potential negative perceptions of plain language in the financial and business sector.

\subsection{The micro level}

Plain language style guide. In addition to a general style guide, institutions must have a dedicated plain language style guide, not only in cases where outsourcing takes place but also for internal departments. Such a style guide should be based on the findings of psycholinguistic research on (i) the ways in which readers typically process texts; and (ii) the linguistic constructions that have been proven to enhance or impede understanding. Reliance on a general institutional style guide is not sufficient to ensure the success of the plain language project.

Revisions based on testing. Although Knight (2006) identifies a number of problems related to objective and subjective tests, institutions can conduct small-scale testing on a limited number of respondents to determine which revisions are required to render a consumer document easier to understand by a particular target readership.

Consistency. A plain language style guide, in addition to a general institutional style guide, will ensure a consistent approach to plain language, both within in the institution and where and when outside agencies and contractors are used. This is particularly important in cases where, for example, the same clause appears in more than one credit agreement.

\section{Conclusion}

Although the findings of this study point to achieving some successes in the banking industry with the implementation of plain language in consumer documents, some problems remain. Despite Knight's (2006) elucidation of the plain language rule and its application, the findings 
of this study suggest that, at least as far as the three major banks who participated in this study are concerned, industry is experiencing practical difficulties in fulfilling the "broad new obligation on creditors to use 'plain language' in every document that the Act requires the lender to provide to a borrower" (2006: 19).

It seems the position papers drafted by these banks do little to provide guidance to those working in the lower echelons of institutions, the level of project in action, resulting in uncertainty and, in turn, some measure of window-dressing. The extent of the alleged windowdressing should be determined in a follow-up study, by examining a selection of documents from each, assessing their quality and possibly also testing them on a sample of real consumers.

What is heartening, is the finding that the interviewees from all three banks agreed that legal documents can be simplified to be understood by people who are not trained in the law and that the plain language initiative is positively perceived in these institutions. Implementation of the proposed model for plain language in the banking sector could go a long way to reduce the stumbling blocks that are still in the way of a successful plain language project. More research on the benefits of plain language in real and tangible terms can also provide an additional impetus to the plain language drive in South Africa, beyond merely compliance to a regulatory requirement.

\section{References}

Cheek, A. 2010. Defining plain language. Clarity 64: 5-15.

Cornelius, E. 2012. 'n Linguistiese ondersoek na die verstaanbaarheid van verbruikersdokumente vir die algemene Afrikaanssprekende publiek. Unpublished doctoral thesis, University of Johannesburg.

Cornelius, E. 2015. Defining 'plain language' in contemporary South Africa. Stellenbosch Papers in Linguistics, 44: 1-18.

De Scally, C. 2015. Towards a language management model for language practice: Processes in translation and editing in corporate language offices. Unpublished master's dissertation, University of Johannesburg.

Gibbons, J. 2003. Forensic linguistics. An introduction to language in the justice system. Malden: Blackwell Publishing.

Gibbons, J. 2004. Language and the law. In A. Davies and C. Elder (Eds.) The handbook of applied linguistics. Malden: Blackwell Publishing Limited. pp. 285-303.

Gill, P., K. Stewart, E. Treasure and B. Chadwick. 2008. Methods of data collection in qualitative research: Interviews and focus groups. British Dental Journal 204: 291-295. doi:10.1038/bdj.2008.192. Available online: http://www.nature.com/bdj/journal/v204/n6/pdf/ bdj.2008.192.pdf (Accessed 12 August 2016).

Henning, E., W. van Rensburg and B. Smit. 2007. Finding your way in qualitative research. Pretoria: Van Schaik Publishers. 
Kahn, E. 2001. Plain English in law and commerce in South Africa. Clarity 46: 3-5.

Kimble, J. 1992. Plain English: A charter for clear writing. Thomas M. Cooley Law Review 9: 1-58.

Kimble, J. 1994-1995. Answering the critics of plain language. The Scribes Journal of Legal Writing 5: 51-85.

Kimble, J. 1998-2000. The great myth that plain language is not precise. The Scribes Journal of Legal Writing 7: 109-118.

Kitzinger, J. 1994. The methodology of focus groups: The importance of interaction between research participants. Sociology of Health and Illness 16(1): 103-121.

Kitzinger, J. 1995. Introducing focus groups. BMJ 311: 299-302.

Knight, P. 2006. Clarity for South Africa's credit consumers. Clarity 56: 19-21.

Krueger, R.A. and M.A. Casey. 2009. Focus groups. A practical guide for applied research. Los Angeles: Sage Publications.

Leedy, P.D. and J.E. Ormrod. 2005. Practical research. Planning and design. Eighth edition. New Jersey: Pearson Merrill Prentice Hall.

Mossop, B. 2007. Revising and editing for translators. Manchester: St. Jerome Publishing.

Plain Language Group of South Africa. 2010. Submission to the Department of Trade and Industry. Unpublished manuscript obtained from the compilers.

Remenyi, D. 2013. Field methods for academic Research. Interviews, focus groups and questionnaires in business and management studies. Reading: Academic Conferences and Publishing International Limited.

Republic of South Africa. 2006. National Credit Act 34 of 2005. Available online: http://www.justice.gov.za/mc/vnbp/act2005-034.pdf (Accessed 9 October 2015).

Republic of South Africa. 2009. Consumer Protection Act 68 of 2008. Available online: http://www.thenct.org.za/NCTDocs/founding-legislation/f8d6f6aa-994d-4305-b3d0ea056416bbd0.pdf (Accessed 9 October 2015).

Schriver, K.A. 1991. Protocol-aided revision. In E.R. Steinberg (Ed.) Plain language: Principles and practice. Detroit: Wayne State University Press. pp. 148-172.

Stewart, D.W., P.N. Shamdasani and D.W. Rook. 2007. Focus groups. Theory and practice. Second Edition. Thousand Oaks: Sage Publications.

Sullivan, R. 2001. The promise of plain language drafting. McGill Law Journal 47: 97-128. 
Webb, V. and K. Kembo-Sure (Eds.) 2004. African voices. An introduction to the languages and linguistics of Africa. Oxford: Oxford University Press.

\section{Appendix}

The following questions were introduced during the three focus group discussions:

\section{The "grand tour" question}

To what extent do you think bank documents can be successfully produced in plain language for the ordinary person to understand without much effort? This was followed with: Has this always been your view, or have you changed your view somewhere along the line?

\section{Data collected on the macro level}

2.1 How familiar are you with the plain language provision in the NCA and the CPA? What guidance did you get from that provision, if any?

2.2 Do you test your plain language documents on real readers at all?

2.3 Does your bank have a language policy?

2.4 How do you ensure that the legality of documents is not compromised by the use of plain language? Describe the processes, if any, that are in place to ensure that legal documents are checked and signed off, after they have been revised for plain language.

\section{Data collected on the meso level}

3.1 Where is the language services unit located in the bank?

3.2 Which approach, or combination of approaches, did/do you follow in relation to the plain language provision in the two acts? Or did you follow a different approach altogether?"

3.3 How do you arrive at decisions about which documents to deal with first? How do you prioritise, as the bank surely has a great number of documents on its books?

3.4 Describe the relationship between different divisions and role-players involved in the plain language project in your bank.

3.5 Who does the actual plain language work in your bank?

3.6 How did the plain language project impact your workload? and How costly is the project?

3.7 Do employees in the language services unit and legal division receive training in the principles of plain language and are they equipped to do plain language work?

3.8 What is the general perception in your institution about plain language: Are people positive or negative towards the notion of plain language?

3.9 Do you believe the plain language project in your institution was/is a success or a failure?

\section{Data collected on the micro level}

4.1 Does your bank have a plain language style guide or checklist?

4.2 How do you ensure consistency (of approach and choices) among all practitioners working on the project? 